\title{
APOA2 Polymorphism in Relation to Obesity and Lipid Metabolism
}

\author{
Moushira Erfan Zaki, ${ }^{1}$ Khalda Sayed Amr, ${ }^{2}$ and Mohamed Abdel-Hamid ${ }^{2}$ \\ ${ }^{1}$ Medical Research Division, Biological Anthropology Department, National Research Centre, Cairo 12622, Egypt \\ ${ }^{2}$ Human Genetics and Genome Research Division, Medical Molecular Genetics Department, National Research Centre, \\ Cairo 12622, Egypt
}

Correspondence should be addressed to Moushira Erfan Zaki; moushiraz@yahoo.com

Received 15 September 2013; Accepted 21 October 2013

Academic Editor: Francisco Blanco-Vaca

Copyright (C) 2013 Moushira Erfan Zaki et al. This is an open access article distributed under the Creative Commons Attribution License, which permits unrestricted use, distribution, and reproduction in any medium, provided the original work is properly cited.

\begin{abstract}
Objectives. This study aims to analysis the relationship between c. $-492 \mathrm{~T}>\mathrm{C}$ polymorphism in $A P O A 2$ gene and the risk for obesity in a sample of Egyptian adolescents and investigates its effect on body fat distribution and lipid metabolism. Material and Methods. A descriptive, cross-sectional study was conducted on 303 adolescents. They were 196 obese and 107 nonobese, aged 16-19 years old. Variables examined included body mass index (BMI), waist circumference (WC), waist to hip ratio (WHR), systolic and diastolic blood pressure (BP), body fat percentage (BF\%), abdominal visceral fat layer, and dietary intake. Abdominal visceral fat thickness was determined by ultrasonography. The polymorphism in the APOA2 c. $492 \mathrm{~T}>\mathrm{C}$ was analyzed by PCR amplification. Results. Genotype frequencies were in Hardy-Weinberg equilibrium. The frequency of the mutant $\mathrm{C}$ allele was significantly higher in obese cases compared to nonobese. After multivariate adjustment, waist, $\mathrm{BF} \%$ and visceral adipose layer, food consumption, and $\mathrm{HDL}-\mathrm{C}$ were significantly higher in homozygous allele CC carriers than TT+TC carriers. Conclusions. Homozygous individuals for the $\mathrm{C}$ allele had higher obesity risk than carriers of the $\mathrm{T}$ allele and had elevated levels of visceral adipose tissue and serum HDL-C. Moreover, the study shows association between the APOA2 c.-492T $>C$ polymorphism and food consumption.
\end{abstract}

\section{Introduction}

Obesity-linked genetic variations in the presence of other routine habits such as smoking, physical inactivity, and unhealthy food intake may greatly raise the risk of a person developing heart diseases (cardiovascular diseases, CVD).

Excess body fat, obesity, is one of the most common disorders in clinical practice. The location of the body fat is a major determinant of the degree of excess morbidity and mortality due to obesity [1]. At least two components of body fat are associated with obesity-related adverse health outcomes. These are the amount of subcutaneous truncal or abdominal fat, and the amount of visceral fat located in the abdominal cavity. Each of these components of body fat is associated with varying degrees of metabolic abnormalities and independently predicts adverse health outcomes. Many complex traits are thought to be inherited since they often run in families. However, these complex traits do not show typical mendelian pedigree patterns. These nonmendelian diseases may depend on several susceptibility loci, with a variable contribution from environmental factors. Discovering the major susceptibility locus may be the key to advances in understanding the pathophysiology of a disease.

There have been several studies using association approaches in order to undertake systematic searches for candidate genes in obesity defined as elevated body mass index $\left(\mathrm{BMI}, \mathrm{kg} / \mathrm{m}^{2}\right)[2]$.

Apolipoprotein A-II (APOA-II) is the second most common protein in high-density lipoproteins. APOA-II appears to impair the reverse cholesterol transport and antioxidant function of high-density lipoprotein, which is consistent with the observation that increased APOA-II levels promote the development of atherosclerosis [3]. APOA2 polymorphism $(-265 \mathrm{~T}>\mathrm{C})$ has been renamed to c. $-492 \mathrm{~T}>\mathrm{C}$, according to the Human Genomic Variation Society version 2012. A functional polymorphism representing a T-to-C substitution 
at the -492 position of this gene has been associated with waist circumference and lower levels of plasma APOA-II in European men [4], suggesting that genetic variation at the APOA2 may be associated with body fat distribution phenotypes. Lower levels of visceral adipose tissue (VAT), both absolute and relative to their total body fat, have been reported in African-American compared with white women $[5,6]$, which may be related to differences in genetic make-up between women of different ethnic backgrounds.

New obesity loci continue to be identified through genome-wide association studies in populations of increasing size and ethnic diversity $[7,8]$ but understanding of the mechanisms by which known genetic variants contribute to obesity remains limited. Several well established obesity candidates encode proteins that appear to modulate obesity risk via energy intake, a key determinant of obesity risk [9].

In a previous investigation carried out on White Americans participating in the Genetics of Lipid Lowering Drugs and Diet Network (GOLDN) study, the recessive effects for the c. $-492 \mathrm{~T}>\mathrm{C}$ polymorphism was observed [10]. Homozygous individuals for the $\mathrm{C}$ allele had higher body mass index (BMI) and obesity risk than the carriers of the $\mathrm{T}$ allele, but relationships between APOA2 c. $492 \mathrm{~T}>\mathrm{C}$ genotype and obesity among Egyptian adolescents are unexplored till now.

Therefore, our objectives were to analyzing the association between the APOA2 c. $492 \mathrm{~T}>\mathrm{C}$ polymorphism SNP and the risk of obesity and study its association with anthropometric measurements, body fat distribution, food consumption, and lipid metabolism in a sample of Egyptian adolescents.

\section{Materials and Methods}

A descriptive cross-sectional study was conducted on randomly selected 303 Egyptian adolescents. They were 196 obese and 107 nonobese. Their age ranged 16-19 years old and the mean age was $17.45 \pm 2.54$ years. Obese cases had BMI greater than 95th percentile for age and gender according to the National Egyptian Growth Curves of Children and Adolescents [11].

The data were collected from June 2011 to July 2012 and were extracted from a project entitled "Obesity among Youth: Lifestyle and Genetic Factors" funded by the Science and Technology Development Fund (STDF), Egypt. This study protocol was approved by the ethical committee board of the National Research Centre of Egypt (no. 10/223). An informed written consent was obtained from all participants. All individuals were clinically evaluated and anthropometric data were collected.

2.1. Anthropometric Measurements. Anthropometric variables including height, weight, waist, and hip were measured. Body weight was measured with the patients in light clothing and without shoes. Height was measured with the patients standing with their backs leaning against the stadiometer of the same scale. BMI was calculated as weight in kilograms divided by height in meters squared $\left(\mathrm{kg} / \mathrm{m}^{2}\right)$. WC and hip circumference $(\mathrm{HC})$ were measured in $\mathrm{cm}$ using a plastic, nonstretchable tailor's tape. WC was measured with light clothing at a level midway between the lower rib margin and the iliac crest standing and breathing normally. HC was measured at the level at the widest circumference over the buttocks (at the greater trochanter). Subsequently, the waist hip ratio (WHR) was calculated as WC divided by HC. Anthropometric measurements were obtained according to standardized equipment and following the recommendations of the International Biological Program [12].

Systolic and diastolic blood pressure (BP) were measured with the patients sitting with their left arm at heart level using a professional Riester sphygmomanometer manufactured in Japan. Several measurements were made, from which an average BP measurement was obtained. BF\% was measured by Tanita Body Composition Analyzer (SC-330).

2.2. Genotyping. Genomic DNA was extracted from peripheral blood leukocytes using GeneJET Genomic DNA Purification Kit-(Fermentas, German) according to the manufacturer instructions. Genotyping of c. $-492 \mathrm{~T}>\mathrm{C}$ polymorphism in the APOA2 gene was carried out using polymerase chain reaction-restriction fragment length polymorphism (PCRRFLP) analysis [4]. Two pair of primers were used to amplify the promoter region of the APOA2 gene containing the polymorphism; upstream primer $5^{\prime} \mathrm{CAT}$ GGG TTG ATA TGT CAG AGC-3' and downstream primer $5^{\prime}$ TCA GGT GAC AGG GAC TAT GG 3'.

PCR was carried out in a $25 \mu \mathrm{L}$ total final volume containing $200 \mu \mathrm{M}$ dNTPs (Finzyme, Finland), 10 pmole of each primer, $2 \mathrm{U}$ of Taq polymerase (Finzyme, Finland), and 500 ng DNA. Thermal cycling conditions were as follows: denaturation at $95^{\circ} \mathrm{C}$ for $10 \mathrm{~min}$, followed by 30 cycles of denaturation at $95^{\circ} \mathrm{C}$ for $30 \mathrm{sec}$, annealing at $59.5^{\circ} \mathrm{C}$ for $30 \mathrm{sec}$, and elongation at $72^{\circ} \mathrm{C}$ for $30 \mathrm{sec}$ followed by a final elongation of $5 \mathrm{~min}$.

Ten $\mu \mathrm{L}$ of successfully amplified PCR products were digested with Fast Digest BsmI enzyme (Fermentas, Germany), incubated at $37^{\circ} \mathrm{C}$ for $5 \mathrm{~min}$ and the fragments were run in 3\% agarose gel stained with ethidium bromide, and analyzed under ultraviolet light. The BsmI enzyme cuts the PCR product $(273 \mathrm{bp}$ ) in two fragments 215 and $58 \mathrm{bp}$ in presence of the $\mathrm{T}$ allele.

2.3. Abdominal Ultrasonographic Examination. Ultrasonography was carried out by using GE logic $\alpha 200$-ultrasound machine. Visceral fat layer was measured from the region just above the umbilicus [13]. The convex-array probe $(3.5 \mathrm{MHz})$ was used for measuring visceral abdominal fat and anterior wall of the aorta.

2.4. Dietary Intake. Food intake carried out using 24 hours dietary recall. Cases were asked to recall their dietary intakes of the previous 24 hours. In particular, we asked about intake of carbonated beverages, juices, and other casual intake. Food frequency method assessed food consumption frequencies per day and week and month basis by using a questionnaire. It was focused on different kinds of food consumption 
TABLE 1: General characteristics of obese and non-obese adolescents.

\begin{tabular}{lcccc}
\hline Parameters & \multicolumn{2}{c}{ Females } & \multicolumn{2}{c}{ Males } \\
& Obese & Non-obese & Obese & Non-obese \\
\hline BMI $\left(\mathrm{kg} / \mathrm{m}^{2}\right)$ & $34.40 \pm 5.96^{* *}$ & $21.99 \pm 3.45$ & $32.75 \pm 6.075^{* *}$ & $19.86 \pm 3.33$ \\
Waist $(\mathrm{cm})$ & $95.90 \pm 12.23^{* *}$ & $72.57 \pm 8.94$ & $98.05 \pm 18.90^{* *}$ & $71.79 \pm 8.54$ \\
WHR & $0.82 \pm 0.06^{* *}$ & $0.77 \pm 0.16$ & $0.88 \pm 0.129^{* *}$ & $0.81 \pm 0.06$ \\
BF\% & $33.74 \pm 13.05^{* *}$ & $30.96 \pm 12.93$ & $33.88 \pm 13.78^{* *}$ & $26.63 \pm 11.61$ \\
Systolic BP $(\mathrm{mmHg})$ & $110.77 \pm 14.81$ & $109.60 \pm 13.09$ & $110.67 \pm 16.37$ & $108.80 \pm 13.23$ \\
Diastolic BP $(\mathrm{mmHg})$ & $71.79 \pm 10.31$ & $71.80 \pm 7.93$ & $71.42 \pm 9.746$ & $73.00 \pm 10.00$ \\
\hline
\end{tabular}

${ }^{* *}$ Statistically significant differences $(P<0.01)$ between obese and non-obese subjects.

TABLE 2: Genotype and allelic distribution of APOA2 c. $-492 \mathrm{~T}>\mathrm{C}$ polymorphisms.

\begin{tabular}{|c|c|c|c|c|c|c|c|}
\hline \multirow{2}{*}{ Polymorphisms } & \multicolumn{3}{|c|}{ Genotypes } & \multicolumn{2}{|c|}{ Alleles } & \multicolumn{2}{|c|}{ Grouped genotypes } \\
\hline & $\mathrm{CC}$ & TC & $\mathrm{TT}$ & $\mathrm{C}$ & $\mathrm{T}$ & $\mathrm{CC}$ & $\mathrm{TT}+\mathrm{TC}$ \\
\hline \multirow{2}{*}{$\begin{array}{l}\text { Controls } \\
(n=107)\end{array}$} & 10 & 64 & 33 & 84 & 130 & 10 & 97 \\
\hline & $9.34 \%$ & $59.81 \%$ & $30.84 \%$ & $39.25 \%$ & $60.74 \%$ & $9.34 \%$ & $90.65 \%$ \\
\hline \multirow{2}{*}{$\begin{array}{l}\text { Obese } \\
(n=196)\end{array}$} & 63 & 62 & 71 & 188 & 204 & 63 & 133 \\
\hline & $32.1 \%$ & $31.6 \%$ & $36.2 \%$ & $47.96 \%$ & $52.04 \%$ & $32.1 \%$ & $67.9 \%$ \\
\hline$P$ value & 0.001 & 0.001 & 0.022 & 0.01 & 0.01 & 0.001 & 0.001 \\
\hline
\end{tabular}

frequencies rather than consumption of specific nutrients. The energy and nutrient contents were computed.

2.5. Biochemical Analyses. HDL cholesterol was measured after precipitation of non-HDL cholesterol with magnesium/ dextran. We measured LDL cholesterol by use of a homogeneous direct method (LDL Direct Liquid Select Cholesterol Reagent; Equal Diagnostics) on the Hitachi autoanalyzer 704 (Roche Diagnostics Switzerland).

2.6. Statistical Analysis. Quantitative variables were expressed as mean \pm S.D., and qualitative variables were expressed as percentages. Differences between groups were tested using an independent two-sample $t$-test and chisquare test was used to test for differences in the distribution of categorical variables. $P$ values $<0.05$ were considered statistically significant.

\section{Results}

The characteristics of the obese cases and nonobese are given in Table 1, where we compare the anthropometric and clinical variables for the obese and nonobese individuals. There were significant differences in $\mathrm{BMI}, \mathrm{WC}, \mathrm{WHR}, \mathrm{BF} \%$, and visceral fat thickness between the two groups. Obese adolescents had higher values than nonobese in both genders. APOA2 genotype frequencies did not deviate from Hardy-Weinberg equilibrium expectations and did not differ between males and females. Therefore, males and females were analyzed together. The genotype and allele distribution are presented in Table 2. The data indicate that genotype tends to differ significantly between obese and nonobese adolescents in the CC and TT genotypes, remaining significant when the genotypes in CC and CT+TT were grouped; the CC genotype
TABLE 3: Associations of APOA2 c.-492T>C polymorphism genotype with anthropometric parameters ${ }^{\mathrm{a}}$.

\begin{tabular}{lcc}
\hline Parameters & $\mathrm{CC}(n=73)$ & $\mathrm{TT}+\mathrm{TC}(n=230)$ \\
\hline BMI $\left(\mathrm{kg} / \mathrm{m}^{2}\right)$ & $32.29 \pm 7.48^{*}$ & $23.77 \pm 8.25$ \\
Waist $(\mathrm{cm})$ & $87.91 \pm 15.81^{*}$ & $82.84 \pm 17.04$ \\
WHR & $0.89 \pm 0.11$ & $0.82 \pm 0.19$ \\
BF\% & $35.69 \pm 11.37^{*}$ & $30.87 \pm 12.43$ \\
Systolic BP $(\mathrm{mmHg})$ & $108.70 \pm 16.24$ & $110.66 \pm 13.89$ \\
Diastolic BP $(\mathrm{mmHg})$ & $71.30 \pm 10.41$ & $72.11 \pm 9.08$ \\
Energy intake $(\mathrm{Kcal} / \mathrm{d})$ & $1957.1 \pm 87.9^{*}$ & $1499.7 \pm 87.1$ \\
Total fat $(\mathrm{g} / \mathrm{d})$ & $93.6 \pm 31.6^{*}$ & $51.5 \pm 29.5$ \\
SATFAT $(\mathrm{g} / \mathrm{d})$ & $33.9 \pm 8.95^{*}$ & $22.2 \pm 7.91$ \\
HDL-C $(\mathrm{mg} / \mathrm{dL})$ & $56.60 \pm 7.88^{*}$ & $38.41 \pm 7.81$ \\
LDL-C $(\mathrm{mg} / \mathrm{dL})$ & $115.68 \pm 38.87$ & $110.64 \pm 36.10$ \\
\hline
\end{tabular}

${ }^{*}$ Statistically significant differences $(P<0.05)$ between CC homozygous subjects and carriers of the $\mathrm{T}$ allele for the corresponding variable.

${ }^{a}$ Data are adjusted for age, gender, and BMI.

was more common in obese cases than in nonobese (CC frequency $32.1 \%$ in obese cases and $9.3 \%$ in lean controls, $P<0.001)$. The allele frequency of the APOA2 c. $-492 \mathrm{~T}>\mathrm{C}$ polymorphism was also significantly different between the two groups (Table 2).

APOA2 genotype was evaluated by comparing homozygous minor allele carriers (CC) with combined homozygous major (TT) and heterozygous (TC) subjects (Table 3). After adjusting for age, sex, and BMI, anthropometric measures showed significant differences between homozygous and heterozygous carriers. $\mathrm{BMI}, \mathrm{WC}, \mathrm{BF} \%$, and visceral fat were significantly higher in CC subjects compared with combined heterozygotes (TC) and homozygous major (TT) carriers 
$(P<0.001)$. Significant elevated HDL-C was observed in CC subjects compared with the carriers of $\mathrm{T}$ allele.

Homozygous individuals for the CC allele had a statistically higher mean of energy intake, total fat intake (g/day), and saturated fat (SATFAT) than carriers of the $\mathrm{T}$ allele.

\section{Discussion}

The present study found strong association between the APOA2 c.-492T>C SNP polymorphism and obesity risk and anthropometric measures. The study observed that $\mathrm{CC}$ homozygotes had higher BMI, WC, BF\%, visceral fat, food consumption, and HDL-C than carriers of the T allele. These results were consistent with the findings of the previous study of overweight individuals in other populations. Relatively few studies reported the association between APOA2 polymorphisms and phenotypic traits [14-17]. Few genetic variants have been identified in the APOA2 gene [18]. Interestingly, a T-C transition at position -492 affecting element of the $A P O A 2$ promoter has been reported to be functional in 2 independent studies, both demonstrating an $-30 \%$ drop in basal transcription activity $[4,19]$. In one of these studies, the APOA2 polymorphism was associated with waist circumference in men [4]. Another study [19] reported an association between this polymorphism and abdominal fat depots in women.

Association between APOA2 c.-492T >C SNP and BMI or obesity only in the presence of high-saturated fat intake in three American populations has been observed [20]. Moreover, with this gene-diet interaction other studies extend the findings to other geographical areas (Europe and Asia), reporting that when saturated fat intake is low $(<22 \mathrm{~g} / \mathrm{d})$, this SNP does not have any effect on BMI or obesity. However, when saturated fat intake is high $(\geq 22 \mathrm{~g} / \mathrm{d})$, significant differences in anthropometric variables were detected between CC individuals and $\mathrm{T}$ allele carriers. Further adjustment for other macronutrients did not change the significance of these findings, supporting the specificity of saturated fat as a driver of this interaction [21]. Moreover, other study reported genotype-associated differences in specific intake-related behaviours, which may contribute to obesity risk, identifying the possible role of ghrelin in modulating APOA2-nutrient interactions [22]. Eating behaviours have been identified as related to obesity risk $[23,24]$ and appear to be associated with APOA2 genotype in a manner consistent with obesity risk. Relationship between $A P O A 2$, saturated fat, and hormonal regulation of food intake has also been identified, which may be relevant to weight control. The interactions between APOA2 and saturated fat for obesity may be mediated via modulation of plasma ghrelin and expansion of knowledge of APOA2 and obesity to include modulation of specific behaviours and hormonal mediators not only broadens understanding of gene-diet interactions, but also facilitates the pragmatic, future goal of developing dietary guidelines based on genotype [22]. Lower saturated fat was associated with lower ghrelin in CC carriers, which may theoretically be expected to accompany lower energy intake and smaller body size.
Despite the scarcity of previous data supporting a role of APOA2 in regulating food intake, numerous experimental evidence demonstrates a pivotal role of another apolipoprotein, APOA4, as a satiety signal $[25,26]$. Fujimoto et al. [25] were the first to report that APOA4 is a satiety factor secreted by the intestine after fat absorption and that this function of APOA4 is not shared by gut APOA1. APOA2 is a member of the apolipoprotein multigene super family, which includes genes encoding soluble apolipoproteins (e.g., APOA1 and APOA4) that share genomic structure and several functions. Although all these apolipoprotein genes have been found to be related to obesity in at least one epidemiological study [27], only APOA4 has been subscribed in regulation of food intake, acting as a satiety signal. The present study shows association between the APOA2 polymorphism and food consumption, suggesting a potential new role of APOA2 in the regulation of human appetite. Moreover, the present study shows that the c. $-492 \mathrm{~T}>\mathrm{C}$ locus is an important genetic determinant of HDL cholesterol concentration. The mechanisms of this proatherogenic capability of increased human apoA-II could be due to increased concentration of apoB-containing lipoprotein and decreased HDL cholesterol, impairment of reverse cholesterol transport due to decreased cholesterol efflux and esterification $[28,29]$.

In summary, the present study emphasized that the homozygous individuals for the CC allele had higher obesity risk than carriers of the $\mathrm{T}$ allele. The functional polymorphism representing a T-to- $C$ substitution at the -492 position of this gene is associated with visceral adipose tissue and food consumption. Moreover, this polymorphism had a significant role on HDL cholesterol concentration and could be a modifier gene for familial combined hyperlipidemia.

\section{Acknowledgment}

The authors are greatly thankful to the Science and Technology Development Fund (STDF) for funding the project entitled "Obesity among Youth: Lifestyle and Genetic Factors" (1225) that enabled us to use the data to establish this work.

\section{References}

[1] P. Björntorp, "Obesity," The Lancet, vol. 350, no. 9075, pp. 423426, 1997.

[2] T. Rankinen, L. Pérusse, S. J. Weisnagel, E. E. Snyder, Y. C. Chagnon, and C. Bouchard, "The human obesity gene map: the 2001 update," Obesity Research, vol. 10, no. 3, pp. 196-243, 2002.

[3] C. H. Warden, C. C. Hedrick, J.-H. Qiao, L. W. Castellani, and A. J. Lusis, "Atherosclerosis in transgenic mice overexpressing apolipoprotein A-II," Science, vol. 261, no. 5120, pp. 469-472, 1993.

[4] F. M. Van't Hooft, G. Ruotolo, S. Boquist, U. De Faire, G. Eggertsen, and A. Hamsten, "Human evidence that the apolipoprotein A-II gene is implicated in visceral fat accumulation and metabolism of triglyceride-rich lipoproteins," Circulation, vol. 104, no. 11, pp. 1223-1228, 2001.

[5] J. B. Albu, L. Murphy, D. H. Frager, J. A. Johnson, and F. X. PiSunyer, "Visceral fat and race-dependent health risks in obese 
nondiabetic premenopausal women," Diabetes, vol. 46, no. 3, pp. 456-462, 1997.

[6] C. Lara-Castro, R. L. Weinsier, G. R. Hunter, and R. Desmond, "Visceral adipose tissue in women: longitudinal study of the effects of fat gain, time, and race," Obesity Research, vol. 10, no. 9, pp. 868-874, 2002.

[7] I. M. Heid, A. U. Jackson, J. C. Randall et al., "Meta-analysis identifies 13 new loci associated with waist-hip ratio and reveals sexual dimorphism in the genetic basis of fat distribution," Nature Genetics, vol. 42, pp. 949-960, 2010.

[8] E. K. Speliotes, C. J. Willer, S. I. Berndt et al., "Association analyses of 249,796 individuals reveal 18 new loci associated with body mass index," Nature Genetics, vol. 42, pp. 937-948, 2010.

[9] S. A. Cole, N. F. Butte, V. S. Voruganti et al., "Evidence that multiple genetic variants of MC4R play a functional role in the regulation of energy expenditure and appetite in Hispanic children," American Journal of Clinical Nutrition, vol. 91, no. 1, pp. 191-199, 2010.

[10] D. Corella, D. K. Arnett, M. Y. Tsai et al., "The $-256 \mathrm{~T}>\mathrm{C}$ polymorphism in the apolipoprotein A-II gene promoter is associated with body mass index and food intake in the genetics of lipid lowering drugs and diet network study," Clinical Chemistry, vol. 53, no. 6, pp. 1144-1152, 2007.

[11] I. Ghalli, N. Salah, F. Hussien et al., "Egyptian growth curves for infants, children and adolescents," in Crecere nel Mondo, A. Satorio, J. M. H. Buckler, and N. Marazzi, Eds., Ferring Publisher, Milan, Italy, 2008.

[12] J. Hiernaux and J. M. Tanner, "Growth and physical studies", in Human Biology: A Guide to Field Methods, J. S. Weiner and S. A. Lourie, Eds., IBP, Oxford, UK; Blackwell Scientific Publications, London, UK, 1969.

[13] F. Armellini, M. Zamboni, L. Rigo et al., "Sonography detection of small intra-abdominal fat variations," International Journal of Obesity, vol. 15, no. 12, pp. 847-852, 1991.

[14] J. Scott, T. J. Knott, and L. M. Priestley, "High-density lipoprotein composition is altered by a common DNA polymorphism adjacent to apoprotein AII gene in man," The Lancet, vol. 1, no. 8432, pp. 771-773, 1985.

[15] G. A. A. Ferns, C. S. Shelley, and J. Stocks, "A DNA polymorphism of the apoprotein AII gene in hypertriglyceridaemia," Human Genetics, vol. 74, no. 3, pp. 302-306, 1986.

[16] M.-C. Vohl, B. Lamarche, J. Bergeron et al., “The MspI polymorphism of the apolipoprotein A-II gene as a modulator of the dyslipidemic state found in visceral obesity," Atherosclerosis, vol. 128, no. 2, pp. 183-190, 1997.

[17] J. M. Martín-Campos, J. C. Escolà-Gil, V. Ribas, and F. BlancoVaca, "Apolipoprotein A-II, genetic variation on chromosome 1q21-q24, and disease susceptibility," Current Opinion in Lipidology, vol. 15, no. 3, pp. 247-253, 2004.

[18] S. M. Fullerton, A. G. Clark, K. M. Weiss et al., "Sequence polymorphism at the human apolipoprotein AII gene (APOA2): unexpected deficit of variation in an African-American sample," Human Genetics, vol. 111, no. 6, pp. 577-578, 2002.

[19] C. Lara-Castro, G. R. Hunter, J. C. Lovejoy, B. A. Gower, and J. R. Fernández, "Apolipoprotein A-II polymorphism and visceral adiposity in African-American and white women," Obesity Research, vol. 13, no. 3, pp. 507-512, 2005.

[20] D. Corella, G. Peloso, D. K. Arnett et al., "APOA2, dietary fat, and body mass index: replication of a gene-diet interaction in 3 independent populations," Archives of Internal Medicine, vol. 169, no. 20, pp. 1897-1906, 2009.
[21] D. Corella, E. S. Tai, J. V. Sorlí et al., "Association between the APOA2 promoter polymorphism and body weight in Mediterranean and Asian populations: replication of a gene-saturated fat interaction," International Journal of Obesity, vol. 35, no. 5, pp. 666-675, 2011.

[22] C. E. Smith, J. M. Ordovás, C. Sánchez-Moreno, Y. C. Lee, and M. Garaulet, "Apolipoprotein A-II polymorphism: relationships to behavioural and hormonal mediators of obesity," International Journal of Obesity, vol. 36, no. 1, pp. 130-136, 2012.

[23] M. D. M. Bibiloni, E. Martinez, R. Llull, M. D. Juarez, A. Pons, and J. A. Tur, "Prevalence and risk factors for obesity in Balearic Islands adolescents," British Journal of Nutrition, vol. 103, no. 1, pp. 99-106, 2010.

[24] D. G. Schlundt, M. K. Hargreaves, and M. S. Buchowski, "The Eating Behavior Patterns Questionnaire predicts dietary fat intake in African American women," Journal of the American Dietetic Association, vol. 103, no. 3, pp. 338-345, 2003.

[25] K. Fujimoto, J. A. Cardelli, and P. Tso, "Increased apolipoprotein A-IV in rat mesenteric lymph after lipid meal acts as a physiological signal for satiation," American Journal of PhysiologyGastrointestinal and Liver Physiology, vol. 262, no. 6, pp. G1002G1006, 1992.

[26] L. Shen, L.-Y. Ma, X.-F. Qin, R. Jandacek, R. Sakai, and M. Liu, "Diurnal changes in intestinal apolipoprotein A-IV and its relation to food intake and corticosterone in rats," American Journal of Physiology-Gastrointestinal and Liver Physiology, vol. 288, no. 1, pp. G48-G53, 2005.

[27] T. Rankinen, A. Zuberi, Y. C. Chagnon et al., "The human obesity gene map: the 2005 update," Obesity, vol. 14, no. 4, pp. 529-644, 2006.

[28] G. Chiesa, C. Parolini, M. Canavesi et al., "Human apolipoproteins A-I and A-II in cell cholesterol efflux: Studies with transgenic mice," Arteriosclerosis, Thrombosis, and Vascular Biology, vol. 18, no. 9, pp. 1417-1423, 1998.

[29] S. Zhong, I. J. Goldberg, C. Bruce, E. Rubin, J. L. Breslow, and A. Tall, "Human ApoA-II inhibits the hydrolysis of HDL triglyceride and the decrease of HDL size induced by hypertriglyceridemia and cholesteryl ester transfer protein in transgenic mice," Journal of Clinical Investigation, vol. 94, no. 6, pp. 2457-2467, 1994. 


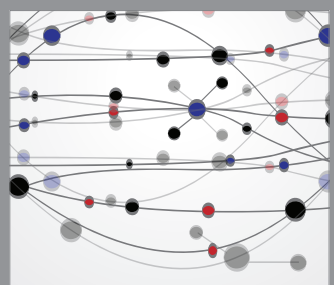

The Scientific World Journal
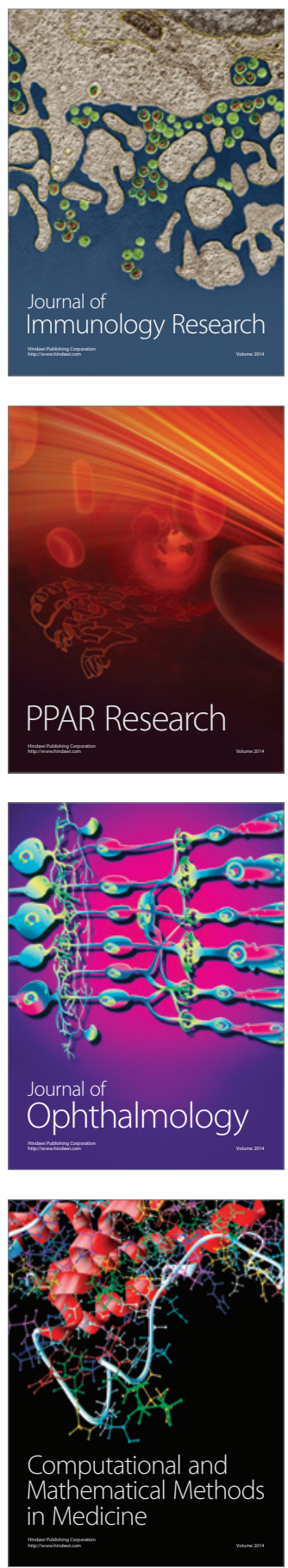

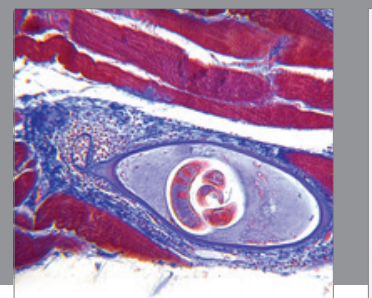

Gastroenterology

Research and Practice
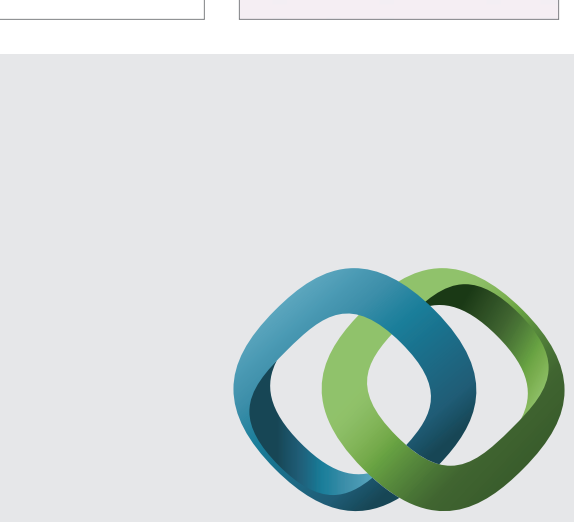

\section{Hindawi}

Submit your manuscripts at

http://www.hindawi.com
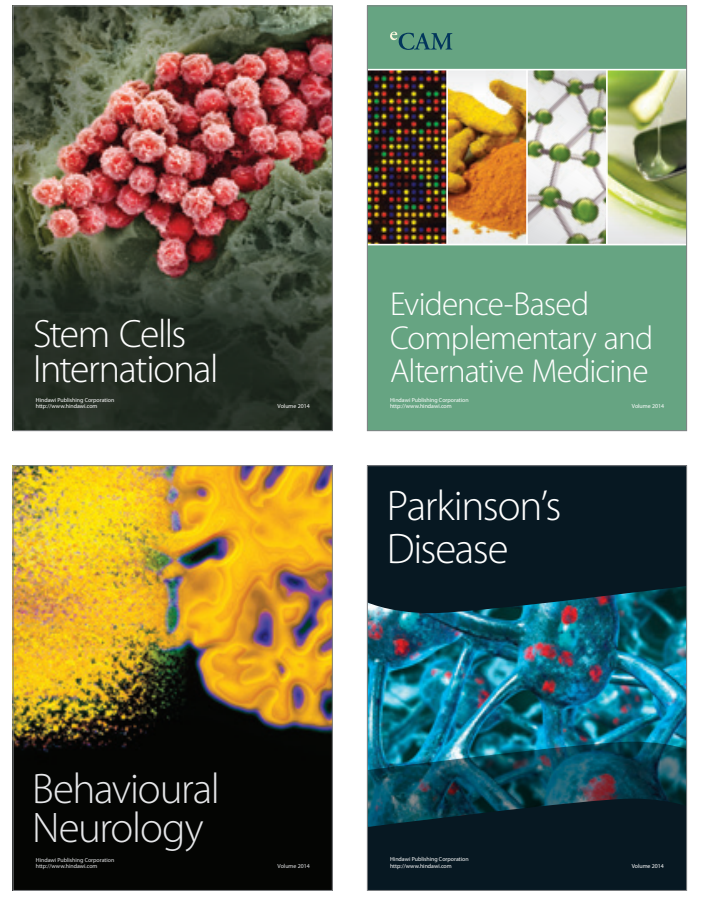
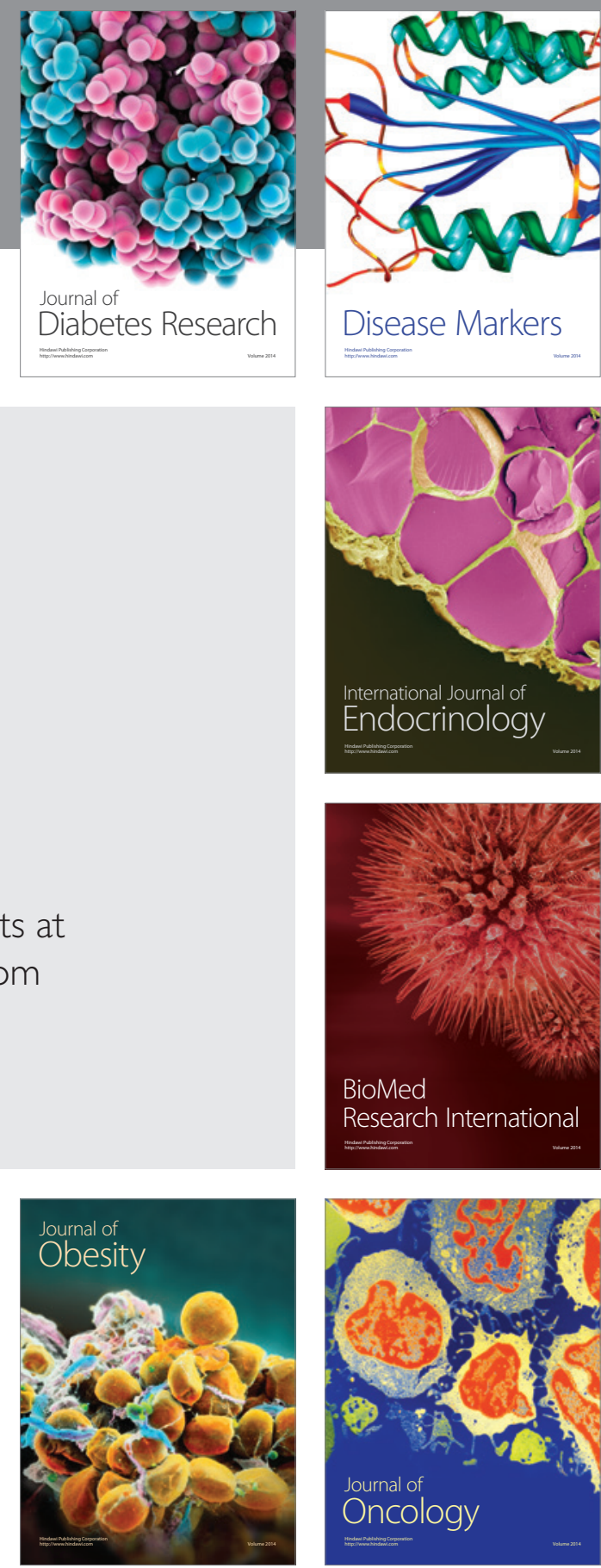

Disease Markers
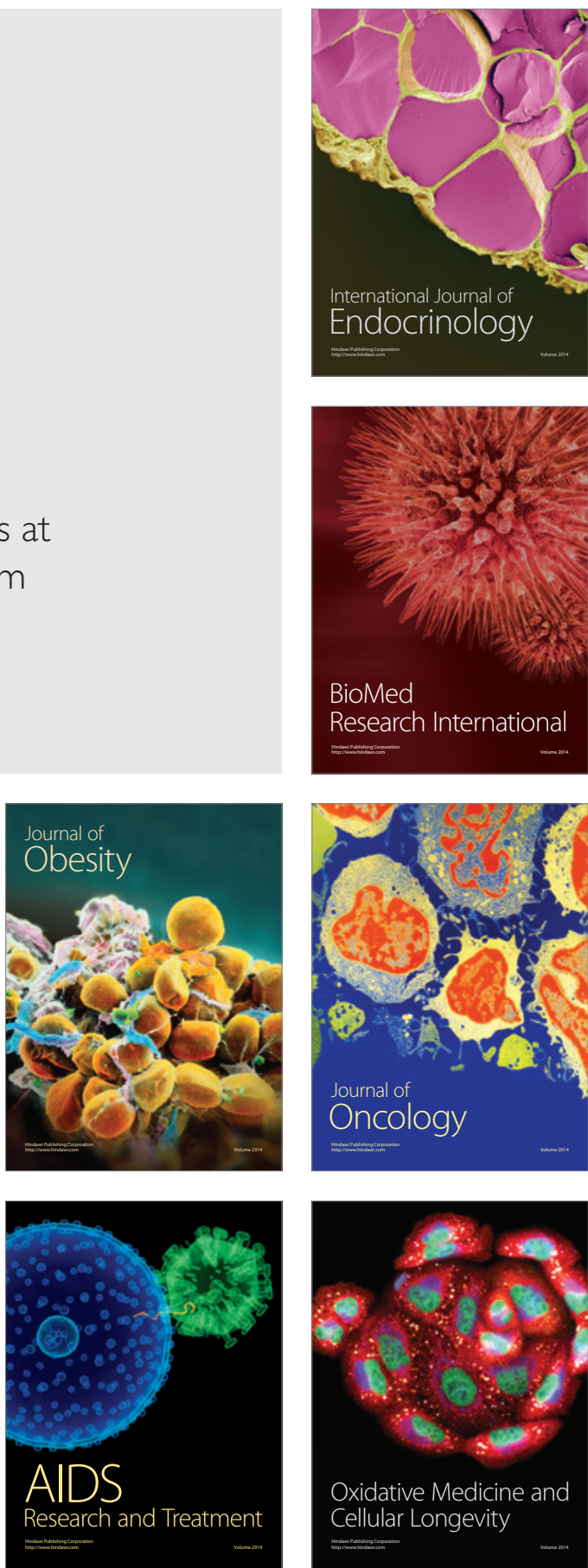